\title{
QUALIDADE FISIOLÓGICA E PRODUTIVIDADE DE SEMENTES DE SOJA
}

\author{
BRUNO RICARDO SCHEEREN², SILMAR TEICHERT PESKE ${ }^{3}$, LUIS OSMAR BRAGA SCHUCH ${ }^{4}$, \\ ANTONIO CARLOS ALBUQUERQUE BARROS ${ }^{4}$
}

\begin{abstract}
RESUMO - A soja constitui, atualmente, assunto de intensa atividade de pesquisa dirigida para a obtenção de informações que possibilitem aumentos de produtividade. Nesse contexto, a utilização de sementes de alta qualidade constitui-se em uma ferramenta de extrema importância para o agricultor. Com o objetivo de avaliar o efeito do vigor na produtividade da soja, seis lotes de sementes, três de alto e três de baixo vigor foram semeados, utilizando-se três densidades de semeadura, determinadas pela germinação do termo de conformidade, mais um fator de correção de $15 \%$ e pelo resultado da emergência no campo. A população de plantas após a emergência não foi alterada com desbaste, buscando assim, reproduzir as condições de campo que o agricultor enfrenta com a semeadura de sementes de qualidade variável. Avaliou-se durante o ciclo de desenvolvimento das plantas, o estande inicial, altura de plantas aos 21 e 75 dias após a semeadura, número de vagens e de sementes por planta e o peso de mil sementes e produção por área. Os resultados obtidos mostram que: a produtividade por área dos lotes de alto vigor pode ser 9\% superior aos de baixo vigor; as plantas provenientes de sementes de alto vigor apresentam maior altura aos 21 dias após a semeadura.
\end{abstract}

Termos para indexação: Glycine max (L.) Merril, estande, produção, germinação, vigor.

\section{PHYSIOLOGICAL QUALITY OF SOYBEAN SEEDS AND PRODUCTIVITY}

\begin{abstract}
There is currently intense research on obtaining information about higher soybean productivity and, in this context, using high quality seeds is extremely important to farmers. With the objective of evaluating the effects of soybean seed vigor on productivity, seed lots with high and low vigor were sown at three different densities: the certified germination $\%$, the certified germination $\%$ plus $15 \%$ as a correction factor and, from the result of field emergence. The seedling population after emergence was not changed so that the field condition that farmers face when sowing variable quality seeds could be reproduced. During plant development, the following parameters were evaluated: initial stand, plant height at 21 and 75 days after sowing, number of pods and seeds per plant, weight of one thousand seeds, and yield/area. The results showed that: the yield/area of high vigor seed lots is on average up to $9 \%$ higher; the seedlings from high vigor seeds are taller at 21 days after sowing.
\end{abstract}

Index terms: Glycine $\max$ (L.) Merril, stand, yield, germination, vigor.

\footnotetext{
${ }^{1}$ Submetido em 05/08/2009. Aceito para publicação em 18/03/2010.

${ }^{2}$ Eng. Agr, Dr., QUALITY- Qualidade em sementes. Rua Eva Rodrigues, 61. Maracaju - MS, 79150-000, e-mail: bruno_ricardo@terra.com.br.
}

${ }^{3}$ Eng. Agr., PhD., Prof. Titular, Depto de Fitotecnia, Ciência e Tecnologia de Sementes, FAEM/UFPel; Cx. Postal 354, 96010-900, Pelotas - RS; e-mail: peske@ufpel.tche.br.

${ }^{4}$ Eng. Agr., Dr., Prof. Adjunto, Depto de Fitotecnia, Ciência e Tecnologia de Sementes, FAEM/UFPel; Cx. Postal 354, 96010-900, Pelotas - RS; e-mail: lobs@ufpel.tche.br; acbarros@ufpel.tche.br. 


\section{INTRODUÇÃO}

O vigor das sementes é um dos principais atributos da qualidade fisiológica a ser considerado na implantação de uma lavoura. Para Tekrony e Egli (1991), o uso de sementes de alto vigor é justificado em todas as culturas, para assegurar adequada população de plantas sobre uma ampla variação de condições ambientais de campo encontradas durante a emergência, e possibilitar aumento na produção quando a densidade de plantas é menor que a requerida.

Sementes com baixo vigor podem provocar reduções na velocidade de emergência, na uniformidade, na emergência total, no tamanho inicial e no estabelecimento de estandes adequados (Höfs, 2003; Machado, 2002; Vanzolini e Carvalho, 2002; Schuch, 1999; Schuch et al., 1999; Schuch e Lin, 1982a), fatores esses que podem influenciar a acumulação de matéria seca, e assim afetar o rendimento (Kolchinski et al., 2005). Em geral, nos trabalhos onde são reportados efeitos significativos de vigor de sementes sobre o rendimento de sementes em culturas anuais, os efeitos normalmente estão associados com densidades populacionais em níveis subótimos (Schuch e Lin, 1982b), ou em semeaduras mais tardias do que o normal (Khah et al., 1989). Marcos Filho e Kikuti (2006) enfatizam que o uso de sementes vigorosas é justificável para assegurar o estabelecimento adequado do estande, mesmo que não haja resposta consistente em termos de produção final das plantas.

Burris (1976) e Roberts (1986) sugeriram que o relacionamento entre vigor de sementes e produtividade, é dependente de quando a avaliação é realizada quer seja no estádio vegetativo ou reprodutivo. Tekrony e Egli (1991), também concluíram que o efeito do vigor de sementes sobre o rendimento de produto econômico, é dependente do estádio em que a cultura é colhida. Culturas colhidas durante crescimento vegetativo ou crescimento reprodutivo precoce, usualmente tem mostrado um relacionamento positivo entre vigor de sementes e rendimento. Entretanto, para culturas colhidas na maturidade, geralmente não tem apresentado relação entre vigor de sementes e rendimento, sob condições normais de cultivo. Assim, vigor de sementes pode afetar o crescimento inicial das culturas, sendo que o efeito tende a se reduzir com a evolução do crescimento (Tekrony et al., 1989). Vanzolini e Carvalho (2002), ao avaliarem lotes de sementes de soja de diferentes níveis de vigor, mas com germinação acima de $75 \%$, concluíram que o desempenho no campo, não resultou em produtividades significativamente diferentes.
Khah et al. (1989) observaram em plantas de trigo sob condições não competitivas, que diferenças no vigor das sementes resultaram em diferenças na taxa de crescimento no período inicial até sete semanas da emergência, tendo ocorrido efeito deletério do baixo vigor das sementes sobre o crescimento de plântulas na fase inicial. Isso permitiu as plantas provenientes de sementes de alta qualidade, uma vantagem inicial que foi suficiente inclusive para resultar em um maior rendimento final de grãos. Em soja, Kolchinski et al., (2005) verificaram que plantas provenientes das sementes de alto vigor apresentam maior índice de área foliar, produção de matéria seca e acréscimos superiores a $35 \%$ no rendimento de sementes, em relação ao uso das sementes de baixo vigor.

Carvalho e Nakagawa (1988) citam vários trabalhos que mostram a influência do nível de vigor sobre a produtividade, sendo freqüente a ocorrência de reduções significativas na produção pelo uso de sementes de baixo vigor. Em milho, Grabe (1966), citado por Carvalho e Nakagawa (1988), registrou redução de até $8 \%$ na produção quando usou sementes de baixo vigor. Sob efeito de competição, a redução foi mais acentuada, até 15\%. Em sorgo, Camargo (1971) citado por Carvalho e Nakagawa (1988), registrou uma redução de 9 \% na produção. Em amendoim, Carvalho e Toledo (1978), citados por Carvalho e Nakagawa (1988), verificaram que plantas provenientes de sementes de baixo vigor produziram $24 \%$ a menos. Esses mesmos autores, concluíram que quanto à produção por planta, a influência do vigor não é tão grande.

No presente estudo foram utilizados lotes de sementes com dois níveis de vigor, utilizando-se três densidades de semeadura ajustadas com base nos resultados da qualidade fisiológica, sem alterar com desbaste a população de plantas obtida após a emergência, buscando assim reproduzir as condições de campo que o agricultor enfrenta com a semeadura de sementes de qualidade variável, visando avaliar o efeito do vigor na produtividade da soja.

\section{MATERIAL E MÉTODOS}

O experimento foi conduzido em condições de campo no ano agrícola 2002/2003, no Centro Experimental da Fundação MS, localizado no município de Maracaju MS, situado na região fisiográfica denominada Serra de Maracaju, a $21^{\circ} 00^{\prime}$ de latitude sul e $55^{\circ} 42^{\prime}$ de longitude oeste. $\mathrm{O}$ solo da região onde foi instalado o experimento pertence à Unidade de Mapeamento Latossolo Roxo Distrófico, textura argilosa. Os resultados da análise de solo apresentaram as 
seguintes características: matéria orgânica: $3,8 \mathrm{~g} \cdot \mathrm{dm}^{-1} ; \mathrm{pH}$ em H20: 6,4; $\mathrm{Al}^{3+}: 0,0 ; \mathrm{Ca}^{2+}:$ 7,7 $\mathrm{cmol}^{-\mathrm{dm}^{-3}} ; \mathrm{Mg}^{2+}: 2,2$ cmol.dm ${ }^{-3}$; P: 12,0 mg.dm ${ }^{-3} ; \mathrm{K}^{+}$: 0,30 cmol.dm ${ }^{-3}$.

A unidade experimental foi composta por 5 linhas espaçadas de 0,45 m com comprimento de $12 \mathrm{~m}$. A área útil de cada parcela $\left(5,4 \mathrm{~m}^{2}\right)$ foi constituída pelas três linhas centrais, excluindo-se 3,0 m de cada extremidade.

Utilizou-se a cultivar Coodetec 202, de ciclo precoce e hábito de crescimento determinado, produzida pela Cooperativa Agropecuária e Industrial na safra de $2001 / 2002$. Os lotes selecionados com os resultados do termo de conformidade foram classificados em alto e baixo vigor, quando apresentavam germinação de $94 \pm 2 \%$ e 83 $\pm 2 \%$, respectivamente. Para efeito de uniformidade, todos os lotes foram avaliados simultaneamente em outubro de 2002, pelos testes de germinação, tetrazólio e emergência no campo, realizados conforme metodologia descrita a seguir:

$\mathrm{O}$ teste de germinação foi realizado de acordo com as Regras para Análise de Sementes (Brasil, 1992), diferindo apenas quanto ao número de sementes, que foram de 200, divididas em quatro repetições de 50 sementes.

Para a emergência no campo foram utilizadas 200 sementes, divididas em duas repetições de 100 sementes por unidade experimental, semeadas em linhas espaçadas de $0,15 \mathrm{~m}$, com uma profundidade de três a cinco $\mathrm{cm}$, contando as plântulas emergidas após 10 dias da semeadura.

No teste de tetrazólio utilizaram-se 100 sementes, divididas em duas repetições de 50 sementes, as quais foram acondicionadas em papel germiteste umedecido e mantidas por 16 horas na temperatura de $25^{\circ} \mathrm{C}$. Decorrido esse período, as sementes foram colocadas em recipientes plásticos (copinhos de café) sendo totalmente submersas na solução de $0,075 \%$ de sal de tetrazólio, permanecendo por 3 horas à temperatura de 35 a $40{ }^{\circ} \mathrm{C}$ em estufa. Posteriormente, as sementes foram lavadas em água comum e mantidas submersas em água até o momento da avaliação, determinando a viabilidade e o vigor através da classificação de cada semente em uma das oito categorias descritas por França Neto et al. (1998).

Os lotes de sementes de alto e baixo vigor foram semeados com semeadora de cinco linhas, utilizando-se três densidades de semeadura. A população de plantas desejada de 350.000 plantas por hectare (16 plantas $/ \mathrm{m}$ ) foi calculada a partir de semeaduras com ajuste no número de sementes de soja em função dos resultados de germinação informados no termo de conformidade (D1), da germinação do termo de conformidade mais um fator de correção de $15 \%$ (D2) e pelo resultado da emergência no campo (D3).
Assim:

Densidade 1 (D1): semeadura de 17 e 20 sementes/m linear para os lotes de alto e baixo vigor, respectivamente.

Densidade 2 (D2): semeadura de 20 e 23 sementes $/ \mathrm{m}$ linear para os lotes de alto e baixo vigor, respectivamente.

Densidade 3 (D3): semeadura de 18 e 25 sementes $/ \mathrm{m}$ linear para os lotes de alto e baixo vigor, respectivamente.

A população de plantas obtida após a emergência, não foi alterada com desbaste, buscando assim reproduzir as condições de campo que o agricultor obtém com a semeadura de sementes de qualidade variável.

A semeadura foi realizada em 15/11/02, em sistema de plantio direto, não sendo necessário realizar correção de acidez e fertilidade, conforme resultados de análise de solo apresentados anteriormente. A adubação foi realizada juntamente com a semeadura, tendo sido aplicados 400 $\mathrm{kg} / \mathrm{ha}$ da fórmula $02-17-17+$ micronutrientes presentes na formulação nas seguintes proporções: $8 \% \mathrm{Ca}, 5 \%$ $\mathrm{S}, 0,22 \% \mathrm{Zn}, 0,11 \% \mathrm{Cu}$ e $0,14 \% \mathrm{~B}$. As sementes foram tratadas com a mistura dos fungicidas Difeconazole (5 g.i.a) + Thiram (70 g.i.a), respectivamente $33 \mathrm{~mL}+$ $140 \mathrm{~mL}$ de produto comercial por $100 \mathrm{~kg}$ de sementes e inoculadas com estirpes especificas de Bradyrhizobium japonicum, em meio turfoso na dose de $500 \mathrm{~g}$ de inoculante por $50 \mathrm{~kg}$ de semente. A dessecação da lavoura para a semeadura foi realizada com os herbicidas 2,4$\mathrm{D}$ (amina) + Glifosato, na dosagem de 1,0 1/ha e 3,0 1/ ha, respectivamente (EMBRAPA, 2000). O controle de invasoras de folhas largas foi realizado pela aplicação do herbicida Fomesafen na dose de 250 g.i.a.ha ${ }^{-1}$, aplicado quando a soja apresentava três trifólios. As gramíneas foram controladas com a aplicação de Haloxyfop-R na dose de 60 g.i.a.ha ${ }^{-1}$, quando a cultura da soja apresentava 5 trifólios (EMBRAPA, 2000). As pragas que necessitaram de controle foram a Anticarsia gemmatalis (lagarta da soja), Piezodorus guildinii (percevejo verde pequeno) e Euschitus heros (percevejo marrom). A lagarta foi controlada com uma aplicação de Endossulfam na dose de 87,5 g.i.a.ha ${ }^{-1}$ e os percevejos com uma aplicação de Metamidofós na dose de 300 g.i.a.ha-1 ${ }^{-1}$ (EMBRAPA, 2000). A colheita foi realizada em 15/04/2003.

Para a avaliação do efeito do vigor da semente, no desempenho vegetativo e reprodutivo da cultura da soja, foram realizadas as seguintes determinações:

Estande - contou-se o número de plantas presentes na parcela útil aos dez dias após semeadura (DAS). O resultado foi expresso em número de plantas por metro linear.

Altura das plantas foi determinada a partir da superfície 
do solo até a extremidade apical da haste principal em dez plantas tomadas ao acaso, situadas em 1 metro linear na linha central da área da parcela, aos 21 e 75 DAS.

O número de vagens por planta e número de sementes por vagens, foi determinada em dez plantas colhidas em sequência na linha central a partir do início da parcela útil.

O rendimento de grãos foi determinado pela colheita de todas as plantas da área útil de $5,4 \mathrm{~m}^{2}$. O resultado foi expresso em kg.ha- ${ }^{-1}$ corrigido para $13 \%$ de umidade, base úmida. Utilizou-se trilhadora estacionária de parcelas para a trilha das vagens e obtenção das sementes, após foram pesadas em balança com precisão de uma casa decimal. Em seguida foi determinado o teor de água e o peso de mil sementes, segundo metodologias descritas nas Regras para Análises de Sementes (Brasil, 1992). O peso foi corrigido para $13 \%$ de umidade, base úmida.

Foram testados em uma combinação fatorial, três lotes de sementes de soja, com dois níveis de vigor e três densidades de semeadura, utilizando o delineamento experimental de fatorial em blocos ao acaso, com três repetições. A análise dos dados foi efetuada no Sistema de Análise Estatística para Microcomputadores - SANEST (Zonta e Machado, 1986). Para a comparação das médias, foi utilizado o teste de Duncan ao nível de 5\% de probabilidade.

\section{RESULTADOS E DISCUSSÃO}

Os resultados das análises para caracterização da qualidade fisiológica das sementes dos lotes de alto e baixo vigor utilizados na semeadura do experimento estão na Tabela 1. Constata-se, que os resultados dos lotes de alto vigor, expressos no termo de conformidade, apresentam uma boa relação com os obtidos nos testes de avaliação da qualidade fisiológica, ao contrário dos de baixo vigor, que não obtiveram um bom desempenho quando submetidos aos testes de emergência no campo e tetrazólio (vigor). Esses resultados reforçam a recomendação de se utilizar um teste de vigor antes da semeadura, pois o valor da germinação expresso no termo de conformidade, quando utilizado de maneira isolada, pode não ser adequado para determinar a densidade de semeadura recomendada e estabelecer um estande adequado.

No estabelecimento do experimento, as chuvas após a semeadura foram insuficientes, prejudicando a obtenção do estande desejado de 350.000 plantas por hectare, mas foi importante para caracterizar o melhor estabelecimento do estande inicial dos lotes de alto vigor. No sistema de plantio direto, normalmente o contato do solo com a semente não é adequado, pois são formados bolsões de ar e estes dificultam a absorção de água e retardam o processo de germinação. Por isso, chuvas após a semeadura são importantes para estabelecer o contato solo-semente. Resultados semelhantes foram obtidos por Hamman et al. (2002) ao estudarem a relação entre o ambiente de semeadura e a qualidade de sementes sobre a emergência de plântulas de soja, verificaram que em condições de estresse as sementes de alto vigor apresentavam melhor desempenho, enquanto que em condições favoráveis a emergência final dos lotes com níveis de vigor diferentes, foi igual. Schuch (1999) também verificou grande redução na emergência a campo de aveia preta com a progressiva diminuição do vigor das sementes.

TABELA 1. Qualidade fisiológica dos lotes de sementes de soja utilizados para semeadura.

\begin{tabular}{cccccc}
\hline \multirow{2}{*}{ Lotes* $^{*}$} & Germinação T.C.** & Germinação & $\begin{array}{c}\text { Emergência } \\
\text { campo }\end{array}$ & \multicolumn{2}{c}{ Tetrazólio } \\
\cline { 5 - 6 } & 81 & 80 & 68 & 79 & 50 \\
1 B & 83 & 81 & 74 & 79 & 51 \\
3 B & 81 & 80 & 69 & 82 & 52 \\
\hline Média & 82 & 80 & 70 & 80 & 51 \\
\hline 1 A & 95 & 92 & 92 & 91 & 76 \\
2 A & 96 & 94 & 95 & 93 & 81 \\
3 A & 95 & 93 & 92 & 94 & 82 \\
\hline Média & 95 & 93 & 93 & 93 & 80 \\
\hline
\end{tabular}

Lotes* $1 \mathrm{~B}, 2 \mathrm{~B}$ e $3 \mathrm{~B}$ - baixo vigor

Lotes* $1 \mathrm{~A}, 2 \mathrm{~A}$ e $3 \mathrm{~A}$ - alto vigor

T.C.** - termo de conformidade 
A análise estatística mostrou significância para a interação nível de vigor e densidade de semeadura para o parâmetro estande inicial, em que se constatou que a emergência média dos lotes de baixo vigor, cuja densidade de semeadura foi ajustada pela germinação e germinação mais $15 \%$ foi significativamente inferior, o mesmo não ocorrendo quando a densidade de semeadura foi ajustada pelos resultados do teste de emergência, daí a interação ter dado significante. Salienta-se que o estande desejado era de 16 plantas $/ \mathrm{m}$, entretanto como pode ser observada na Tabela 2, a diferença entre o desejado e o obtido foi grande apenas atenuado quando a densidade de semeadura foi em função da germinação mais $15 \%$ para as sementes oriundas de lotes de alto vigor. Estas diferenças podem ser explicadas pela metodologia adotada na condução do teste de emergência no campo, onde as sementes são semeadas a uma profundidade de 3 a $4 \mathrm{~cm}$, em solo preparado e com umidade adequada até a emergência das plântulas, não permitindo assim uma condição de estresse para a semente e plântula. Para a obtenção de um estande de plantas com sementes de baixo vigor, similar ao obtido com sementes de alto vigor, foi necessário aumentar em torno de $47 \%$ a quantidade de sementes por hectare e assim mesmo houve diferença na produtividade, indicando que o estande em si pode não ser suficiente para explicar diferença de produtividade.

TABELA 2. Estande inicial de plantas por metro linear aos 10 DAS, em resposta ao vigor de sementes de soja, semeadas em três densidades de plantio.

\begin{tabular}{lcc}
\hline \multirow{2}{*}{ Densidade } & \multicolumn{2}{c}{ Vigor de sementes } \\
\cline { 2 - 3 } & Alto & Baixo \\
\hline $\mathrm{D} 1 *$ & $12,3 \mathrm{Ab}$ & $10,2 \mathrm{Bc}$ \\
$\mathrm{D} 2 * *$ & $14,7 \mathrm{Aa}$ & $11,7 \mathrm{Bb}$ \\
$\mathrm{D} 3 * * *$ & $12,6 \mathrm{Ab}$ & $12,9 \mathrm{Aa}$ \\
\hline $\mathrm{CV}(\%)$ & \multicolumn{3}{c}{4.9} \\
\hline
\end{tabular}

Médias seguidas da mesma letra maiúscula na linha e minúscula na coluna, não diferem estatisticamente pelo teste de Duncan, ao nível de $5 \%$ de probabilidade.

D1*: semeadura de 17 e 20 sementes/m linear para os lotes de alto e baixo vigor, respectivamente.

D2**: semeadura de 20 e 23 sementes/m linear para os lotes de alto e baixo vigor, respectivamente.

D3***: semeadura de 18 e 25 sementes/m linear para os lotes de alto e baixo vigor, respectivamente.
Para todos os outros parâmetros de avaliação a análise estatística dos dados mostrou significância apenas para níveis de vigor. Assim, para altura de plantas determinada aos 21 dias após a semeadura (Tabela 3), as sementes de alto vigor apresentaram um desempenho $11,5 \%$ superior com uma diferença de $2,5 \mathrm{~cm}$ entre as plantas, que se manteve até aos 75 dias após a semeadura. Isso permitiu que as plantas provenientes de sementes de alta qualidade, uma vantagem desde o inicio contribuindo para resultar em uma maior produtividade grãos (Tabela 3). Efeitos do vigor das sementes no desenvolvimento das plantas, também foram constatados em outros trabalhos (Vanzolini e Carvalho, 2002; Machado, 2002; Schuch et al., 1999, Höfs et al., 2004).

TABELA 3. Altura de plantas em $\mathrm{cm}$ aos 21 e 75 DAS vagens por planta, sementes por planta, peso 1.000 sementes e produtividade $\mathrm{em} \mathrm{kg} /$ ha, em função de níveis de vigor de sementes de soja.

\begin{tabular}{lccc}
\hline \multirow{2}{*}{\multicolumn{1}{c}{ Parâmetro }} & \multicolumn{3}{c}{ Vigor de sementes } \\
\cline { 2 - 4 } & Alto & Baixo & CV (\%) \\
\hline Altura 21 dias (cm) & $13.1 \mathrm{~A}$ & $11.6 \mathrm{~B}$ & 8,6 \\
Altura 75 dias (cm) & $76.4 \mathrm{~A}$ & $73.8 \mathrm{~B}$ & 8,2 \\
Vagem/planta $\left(\mathrm{n}^{\circ}\right)$ & $49.1 \mathrm{~A}$ & $48.9 \mathrm{~A}$ & 8,2 \\
Sementes/planta (n $\left.{ }^{\circ}\right)$ & $92.6 \mathrm{~A}$ & $92.8 \mathrm{~A}$ & 6,9 \\
Peso 1.000 semente (g.) & $139,6 \mathrm{~A}$ & $135,9 \mathrm{~B}$ & 2,5 \\
Produtividade $(\mathrm{Kg} / \mathrm{ha})$ & $3.495 \mathrm{~A}$ & $3.184 \mathrm{~B}$ & 6,1 \\
\hline
\end{tabular}

Média seguida da mesma letra na linha não difere estatisticamente pelo teste de Duncan ao nível de $5 \%$ de probabilidade.

O número médio de vagens produzidas por planta (Tabela 3), não apresentam diferenças significativas, possivelmente devido ao estande de todos os tratamentos serem similares. Um dos componentes da planta que contribui para a maior tolerância à variação na população é o número de vagens por planta que varia inversamente ao aumento ou redução da população. Resultados obtidos por Popinigis (1973) mostram que o número de vagens e de sementes por planta, esta diretamente relacionada com a população de plantas, quanto maior a densidade de plantas por $\mathrm{m}^{2}$ menor o número de vagens. Carpenter e Board (1997) postulam a existência de uma relação inversa entre população de plantas e o número de vagens. Kolchinski et al., (2005) relatam que o maior rendimento das plantas oriundas das sementes de alto vigor foi 
devido, principalmente, ao maior número de vagens por planta, porém, Vanzolini e Carvalho (2002), salientam que o número médio de vagens produzidas por planta, é maior nos lotes de menor vigor, que apresentam menor estande. O rendimento de grãos de soja é determinado pelo número médio de plantas por área, de legumes por área, de grãos por legume e peso médio dos grãos. O número médio de sementes por planta de soja em resposta ao vigor (Tabela 3), não apresentou diferenças significativas entre os níveis de vigor, porém, o peso de mil sementes (Tabela 3) apresentou uma diferença significativa entre os lotes de alto e baixo vigor. Em relação à produtividade constatou-se efeito significativo do nível de vigor, em que as sementes oriundas de lotes de alto vigor apresentam um acréscimo de $9 \%$ na produtividade, o que representa 0,3 ton/ha a mais por hectare. Esses resultados, da mesma forma que os obtidos por Popinigis (1973), Kolchinski (2005) e Mielezrski et al. (2008), demonstram que além de proporcionar maior potencial de rendimento, a utilização de sementes de alto vigor proporciona o estabelecimento de um estande adequado, que na agricultura moderna é a chave do sucesso de um empreendimento agrícola.

No presente estudo o efeito do vigor na produtividade foi significativo independentemente do estande o que reforça resultados de outros trabalhos que encontraram relação estreita entre alto vigor de semente e maior uniformidade entre as plantas originadas desses lotes como constatado por Cantarelli (2005) com soja. A maior desuniformidade entre as plantas produzidas pelos lotes de menor vigor proporciona a ocorrência de plantas dominantes e de plantas dominadas dentro dessas comunidades resultantes, o que poderia contribuir também para reduções no rendimento de grãos das comunidades originadas com lotes de sementes de menor vigor. Outro aspecto, é que se pode ter um mesmo estande, entretanto com uma má distribuição das plantas na linha de semeadura o que afeta o rendimento do cultivo. Lotes de sementes de baixo vigor apresentam maior probabilidade de ter uma má distribuição das plantas, em virtude da necessidade de semeadura ser maior o que foi constatado também neste trabalho (Tabela 2).

\section{CONCLUSÕES}

Sementes de lotes de alto vigor proporcionam maior produtividade e as plantas provenientes de sementes destes lotes apresentam maior altura até aos 75 dias após a semeadura.

\section{REFERÊNCIAS}

BRASIL. Ministério da Agricultura e Reforma Agrária. Secretaria Nacional de Defesa Agropecuária. Departamento Nacional de Produção Vegetal. Coordenação de Laboratório Vegetal. Regras para análise de sementes. Brasília, DF, 1992. 365p.

BURRIS, J.S. Seed/seedling vigor and field performance. Journal of Seed Tecnology, v.1, p.58-74, 1976.

CANTARELLI, L.D. Distribuição espacial e comportamento individual de plantas em função da qualidade fisiológica das sementes, em populações de soja. 2005. 37f. Dissertação (Mestrado em Ciência e Tecnologia de Sementes) - Faculdade de Agronomia Eliseu Maciel, Universidade Federal de Pelotas, 2004.

CARPENTER, A.C.; BOARD, J.E. Branch yield components controlling soybean yield stability across plant populations. Crop Science, v.3, p.755-761, 1997.

CARVALHO, N.M.; NAKAGAWA, J. Sementes: ciência, tecnologia e produção. Campinas: Fundação Cargill, 1988. $424 \mathrm{p}$.

EMPRESA BRASILEIRA DE PESQUISA AGROPECUÁRIA. Embrapa Agropecuária Oeste. Soja: recomendações técnicas para Mato Grosso do Sul e Mato Grosso. Dourados: Embrapa Agropecuária Oeste, 2000. 176p. (Embrapa Agropecuária Oeste. Circular Técnica, 6).

FRANÇA NETO, J.de B.; KRZYZANOWSKI, F.C.; COSTA, N.P. da $O$ teste de tetrazólio em sementes de soja. Londrina: EMBRAPA-CNPSo, 1998. 72p. (Embrapa - CNPSo. Documentos 116).

HAMMAN, B.; EGLI, D.B.; KONING, G. Seed vigor, soil borne pathogens, preemergent growth, and soybean seedling emergence. Crop Science, v.42, p.451-457, 2002.

HÖFS, A.; SCHUCH, L.O.B.; PESKE, S.T.; BARROS, A.C.S.A. Efeito da qualidade fisiológica das sementes e da densidade de semeadura sobre o rendimento de grãos e qualidade industrial em arroz . Revista Brasileira de Sementes, v.26, n.1, p.55-62, 2004a.

HÖFS, A.; SCHUCH, L.O.B.; PESKE, S.T.; BARROS, A.C.S.A. Emergência e crescimento de plântulas de arroz em resposta à qualidade fisiológica de sementes. Revista Brasileira de Sementes, v.26, n.1, p.92-97, 2004.

KHAH, E.M.; ROBERTS, E.H.; ELLIS, R.H. Effects on seed ageing on growth and yield of spring wheat at different plant-population densities. Field Crops Research, v.20, p.175-190, 1989. 
KOLCHINSKI, E.M.; SCHUCH, L.O.B.; PESKE, S.T. Vigor de sementes e competição intra-específica em soja. Ciência Rural, v.35, n.6, p.1248-1256, 2005.

MACHADO, R.F. Desempenho de aveia - branca (Avena sativa L.) em função do vigor de sementes e população de plantas. 2002. 46f. Tese (Doutorado em Ciência e Tecnologia de Sementes) - Curso de Pós-graduação em Ciência e Tecnologia de sementes, Universidade Federal de Pelotas, Pelotas, 2002.

MARCOS FILHO, J.; KIKUTI, A.L.P. Vigor de sementes de rabanete e desempenho de plantas em campo. Revista Brasileira de Sementes, v.28, n.3, p.44-51, 2006.

MIELEZRSKI, F.; SCHUCH, L.O.B.; PESKE, S.T.; PANOZZO, L.E.; PESKE, F.T.; CARVALHO, R.R. Desempenho individual e de populações de plantas de arroz híbrido em função da qualidade fisiológica das sementes. Revista Brasileira de Sementes, v.30, n.3, p.86-94, 2008.

POPINIGIS, F. Effects of the physiological quality of seed on field performance of soybeans (Glycine Max (L.) Merril) as affected by population density. 1973. 87f. Thesis $(\mathrm{PhD}$ in Agronomy) - Mississipi State University.

ROBERTS, E.H. Quantifying seed deterioration. In: M.B. McDONALD Jr.; C.J. NELSON (Ed.). Physiology of seed deterioration. Madison: ASA/CSSA/SSSA, Spec. Publ., 11, 1986. p.101-123.

SCHUCH, L.O.B.; NEDEL, J.L.; ASSIS, F.N.; MAIA, M.S. Crescimento em laboratório de plântulas de aveia- preta (Avena strigosa Schreb.) em função do vigor das sementes. Revista Brasileira de Sementes, v.21, n.1, p.229234.1999.

SCHUCH, L.O.B.; Lin, S.S. Atraso na colheita sobre emergência no campo e desempenho de plantas de trigo. Pesquisa Agropecuária Brasileira, v.17, n.11, p.15851589.1982a.

SCHUCH, L.O.B.; Lin, S.S. Efeito do envelhecimento rápido sobre o desempenho de sementes e plantas de trigo. Pesquisa Agropecuária Brasileira, v.17, n.8, p.1163-1170.1982b.

TEKRONY, D.M.; EGLI, D.B. Relationship of seed vigor to crop yield: A review. Crop Science, v.31, p.816-822, 1991.

TEKRONY, D.M.; EGLI, D.B.; WICKHAM, D.A. Corn seed vigor effect on no-tillage field performance. II. Plant growth and grain yield. Crop Science, v.29, p.1528-1531, 1989.

VANZOLINI, S.; CARVALHO, N.M. Efeito do vigor de sementes de soja sobre o seu desempenho em campo. Revista Brasileira de Sementes, v.24, n.1, p.33-41, 2002.

ZONTA, E.P.; MACHADO, A.A. Sistema de análise estatística para microcomputadores - SANEST. Pelotas: UFPel, Instituto de Física e Matemática, Departamento de Estatística, 1986, 150p. 